\title{
Global lung health: the colliding epidemics of tuberculosis, tobacco smoking, HIV and COPD
}

\author{
R.N. van Zyı Smit*, M. Pai ${ }^{\#}$, W.W. Yew ${ }^{\top}$, C.C. Leung ${ }^{+}$, A. Zumla ${ }^{\S}$, \\ E.D. Bateman* and K. Dheda*, ${ }^{*, f}$
}

ABSTRACT: Tuberculosis (TB), smoking, HIV and chronic obstructive pulmonary disease (COPD) are burgeoning epidemics in developing countries. The link between TB and HIV is well established. Less well recognised is the strong relationship between tobacco smoking and the development and natural history of TB. These associations are of considerable relevance to public health and disease outcomes in individuals with TB. Moreover, tobacco smoking, a modifiable risk factor, is associated with poorer outcomes in HIV-associated opportunistic infections, of which TB is the commonest in developing countries. It is now also becoming clear that TB, like tobacco smoke, besides its known consequences of bronchiectasis and other pulmonary morbidity, is also a significant risk factor for the development of COPD. Thus, there is a deleterious and synergistic interaction between TB, HIV, tobacco smoking and COPD in a large proportion of the world's population. Further work, specifically mechanistic and epidemiological studies, is required to clarify the role of tobacco smoke on the progression of TB and HIV infection, and to assess the impact of smoking cessation interventions. These interactions deserve urgent attention and have major implications for coordinated public health planning and policy recommendations in the developing world.

KEYWORDS: Chronic obstructive pulmonary disease, HIV, smoking, tuberculosis

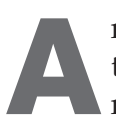

$n$ association between tobacco smoke and tuberculosis (TB) has been debated for nearly 100 yrs [1]. There is now considerable evidence confirming the presence, strength and consistency of this association and the different levels at which it operates. Indoor air pollution is a second risk factor for TB and, although often linked with passive smoke inhalation, emerges as an independent risk factor in epidemiological studies [2-4]. By contrast, the interaction between TB and HIV infection became evident soon after the HIV epidemic commenced, and new associations continue to be recognised, including treatment-related complications and drug interactions [5]. More recently, research has focused on the role of tobacco smoke in patients at risk of infection or infected with HIV $[4,6]$. In this perspective we further highlight the potential associations linking tobacco smoke, air pollution, TB and HIV with the development of chronic obstructive pulmonary disease (COPD) and chronic pulmonary disability (fig. 1).

Recent predictions based upon current exposures to risk factors and disease trends suggest that COPD will become the third commonest cause of death globally by the year 2030, eclipsing deaths from HIV and TB [7]. This dramatic prediction is based on the fact that the epidemic will centre on the large populations of developing countries in Africa, Asia, the Indian subcontinent and China, where there is not only an increasing uptake of tobacco smoking through the targeted marketing strategies of tobacco companies, but also in many countries a high and rising prevalence of cofactors such as air pollution and respiratory infections,

Earn CME accreditation by answering questions about this article. You will find these at the back of the printed copy of this issue or online at www.erj.ersjournals.com/misc/cmeinfo.dtl

\section{AFFILIATIONS}

*Lung Infection and Immunity Unit, Division of Pulmonology and UCT Lung Institute, Dept of Medicine, University of Cape Town, Institute of Infectious Diseases and Molecular Medicine, University of Cape Town, Cape Town, South Africa, \#Dept of Epidemiology, Bio-statistics and Occupational Health, McGill University, Montreal, QC, Canada, "Tuberculosis and Chest Unit, Grantham Hospital, Hong Kong, +Tuberculosis and Chest Service, Centre for Health Protection, Dept of Health, Hong Kong, China, and ${ }^{\S}$ Centre for Infectious Diseases and International Health, University College Medical School, London, UK.

CORRESPONDENCE

R.N. van Zyl Smit Division of Pulmonology, Dept of Medicine, J Floor OMB Groote Schuur Hospital Observatory

7925

Cape Town

South Africa

E-mail: rvzs@iafrica.com

Received:

May 052009

Accepted after revision:

July 192009 
important in the pathogenesis of COPD $[8,9]$. Evidence for this demographic shift towards an ageing population and the developing world is already evident in the results of prevalence surveys of COPD [10]. Unlike the smoking "epidemic" in the developed world, which occurred at a time when exposure to TB and environmental pollution was decreasing, the modern COPD epidemic is, in addition, being fuelled by industrialisation and the rampant spread of TB and HIV [10-13]. The extent to which these factors interact in both additive and synergistic ways to produce chronic lung disease, and especially chronic diseases of the airways, is only now being realised.

This perspective article aims to highlight these potential interactions and their public health implications. We present each interaction separately, and review the possible biological mechanisms involved. Finally, we discuss their potential combined impact and propose strategies for addressing these colliding epidemics.

\section{METHODOLOGY AND SEARCH STRATEGY}

We searched PubMed for peer-reviewed literature published over the last three decades with a focus on studies that reported data on the associations between smoking, TB, COPD and HIV. No language restrictions were imposed, although only English language studies were eventually included. In addition, we identified three systematic reviews [2-4] on the association between tobacco and TB, one systematic review on the association between tobacco and HIV [14] and several narrative reviews [15-19] on the association between tobacco and all the conditions of interest. The reference lists of these reviews were also used to supplement the search. In addition, we identified a comprehensive report entitled "A WHO/The Union monograph on TB and tobacco control: joining efforts to control two related global epidemics" [20]; this was used as an additional resource to complement our searches. Key words included TB, HIV, COPD and tobacco smoking.

\section{SIZE OF THE TB, HIV SMOKING AND COPD EPIDEMICS}

One-third of the world's population, or 2 billion people, is thought to be latently infected with Mycobacterium tuberculosis. The latest estimates from the World Health Organization are that in 2007 there were 9.3 million new TB cases, including 0.5 million cases of multidrug-resistant (MDR)-TB and 1.8 million TB deaths [21]. By the end of that year, 33 million people (range 30-36 million) were living with HIV, 2.7 (range 2.2-3.2) million people had become infected in that year and 2.1 million died of AIDS [22]. AIDS remains the leading cause of death in Africa. To date only one-third of the estimated 9.7 million people needing antiretroviral therapy under current treatment recommendations have received therapy [23]. Around 0.45 million patients co-infected with HIV died of TB in 2007 [21], and TB is the leading cause of death among people living with $\mathrm{HIV}$, even in those receiving antiretroviral therapy. The emergence of drug-resistant TB in countries with a high HIV prevalence poses an additional public health threat, not only to people with HIV but also to the broader community.

In 2006, approximately 5.763 trillion cigarettes were manufactured, an average of 2.4 per day for all 6,528,051,823 inhabitants of the world [2]. Current estimates of tobacco smoking rates are $49 \%$ for males and $8 \%$ for females in low- and middle-income countries, and $37 \%$ for males and $21 \%$ for females in highincome countries [2]. Tobacco is the single most preventable cause of death in the world today. It kills more than 5 million people per year, with more than $80 \%$ of those deaths occurring in the developing world [24].

The Global Burden of Disease and Risk Factors project confirmed that, in 2004, COPD was the fourth leading cause of death worldwide, accounting for $5.1 \%$ of total deaths [7]. A further estimate is that, in high-income countries, $73 \%$ of COPD mortality is related to smoking, while in low- to middleincome countries only $40 \%$ is related to smoking and a further

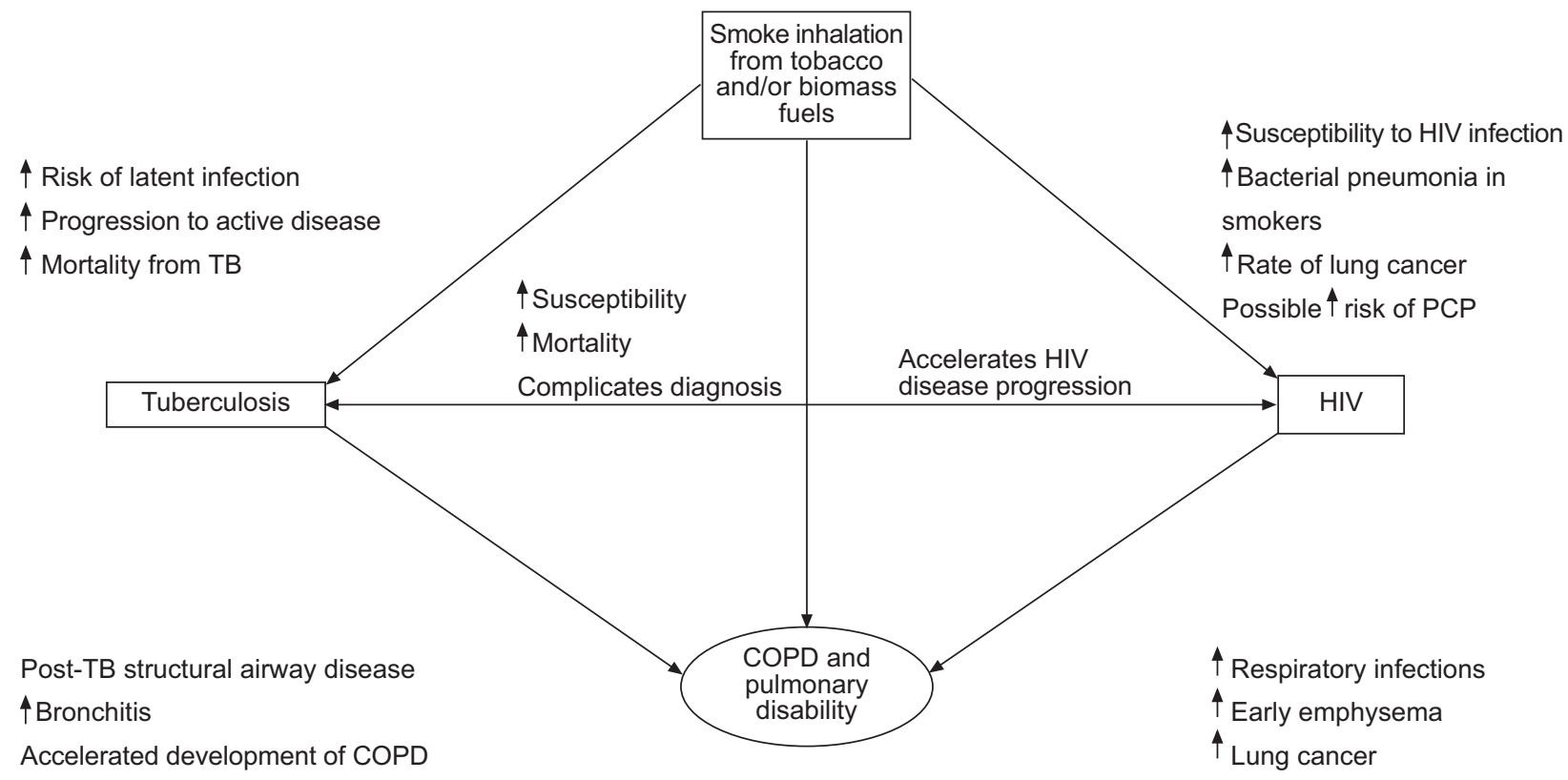

FIGURE 1. Potential interactions between tobacco smoking, HIV, tuberculosis (TB) and chronic obstructive pulmonary disease (COPD) with resultant pulmonary disability. PCP: Pneumocystis jiroveci pneumonia. 
$35 \%$ to indoor smoke from biomass fuels [25]. Furthermore, it is suggested that $36 \%$ of mortality from lower respiratory disease as a whole is related to indoor smoke exposure; by contrast, urban air pollution is responsible for only $1 \%$ of COPD cases in high-income countries and $2 \%$ in low- and middle-income countries [25].

Although the effect is quite consistent across meta-analyses, the estimated relative risk (RR) is modest. The real impact of any risk factor is determined by the magnitude of the association (i.e. RR), and the prevalence of the exposure in the population. Thus, even if the true effect is modest, the population-attributable risk (PAR) is likely to be substantial because of the widespread nature of tobacco exposure. Multiple risk factors are often involved for common diseases, and the PARs of the individual factors are usually estimated in a multiplicative model that assumes mutual independence of the factors. From this model, the overall impact (combined attributable risk) of $\mathrm{n}$ independent factors may be given by the following formula:

$$
\text { Combined } \mathrm{PAR}=\prod_{i=1}^{n}(1-\mathrm{PAR})
$$

where PARi is the PAR of the $\mathrm{i}^{\text {th }}$ individual risk factors.

This formula has been applied to the estimation of the combined effect of smoking and solid fuels (biomass fuels plus coal) in China, where the national adult smoking prevalence was $49.6 \%$ for males and 3\% for females in 2003 and more than $70 \%$ of Chinese households use solid fuels, such as wood, crop residues and coal, for heating and cooking [26]. In that study, $82 \%$ of COPD deaths and $75 \%$ of lung cancer deaths were attributable to the combined effects of smoking and solid-fuel use. In reality, many risk factors tend to be clustered in vulnerable populations, and the assumption of independence used in the above formula may not hold entirely. The excess number of cases among population groups with over-concentration of risk factors generally outweighs the reduction among less affected population groups, thus the actual impact could even be larger.

The situation is more complex for an infectious disease like TB, because infected patients also act as sources for sustaining infection in the population, and risk factors like smoking and solid-fuel use may affect multiple steps, from infection to disease and death. In the above-mentioned study, a deterministic compartmental susceptible-latent-infectious-recovered model was applied for estimation of disease trend. In that model, complete cessation of smoking and solid-fuel use by 2033 would reduce the projected annual TB incidence in 2033 by $14-52 \%$ if $80 \%$ directly observed treatment, short course (DOTS) coverage is sustained, $27-62 \%$ if $50 \%$ DOTS coverage is sustained or $33-71 \%$ if $20 \%$ DOTS coverage is sustained [26]. With the potential clustering and mutual interaction of smoking, solid-fuel use, HIV and TB in underprivileged populations/population groups, even figures of such magnitude could have been underestimated.

\section{ASSOCIATION BETWEEN TOBACCO SMOKING AND TB}

Although the association between tobacco smoke and TB has been debated for over a century [1], only recently has clear epidemiological evidence emerged. Evidence of the impact of tobacco smoking on TB infection has been confounded by its almost universal association with poverty, overcrowding and alcohol usage. In the past few years, three independent systematic reviews and meta-analyses have synthesised a large body of evidence on tobacco and TB [2-4]. These reviews summarise evidence of the association between active smoking and three TB outcomes: TB infection (detected using tuberculin skin testing), active TB disease and mortality due to TB. Table 1 provides an overview of the outcome-specific pooled RR estimates from three independent meta-analyses.

These analyses indicate that smokers are almost twice as likely to be infected with TB and to progress to active disease (RR of $\sim 1.5$ for latent TB infection (LTBI) and RR of $\sim 2.0$ for TB disease). Smokers are also twice as likely to die from TB (RR of $\sim 2.0$ for TB mortality), but data are difficult to interpret because of heterogeneity in the results across studies. Evidence is strong for TB disease, but less strong for TB infection and TB mortality. These associations also pass the test of biological plausibility.

The association between tobacco and TB is now clear enough to demand attention both from practising clinicians as well as policy-makers. For example, if the RR for TB disease is conservatively assumed to be only 1.5 , with $30 \%$ of the population exposed to tobacco smoke, the PAR will be about $13 \%$. In other words, $13 \%$ of the TB cases in the world each year may be attributable to tobacco exposure [19]. Tobacco cessation must become an integral part of all TB control programmes. Recognising this, the International Union Against Tuberculosis and Lung Disease, supported by the Bloomberg Initiative to Reduce Tobacco, has put together several resources for tobacco cessation in TB patients [2]. The extent to which such interventions will have an impact on TB control remains unclear. Benefits of quitting to the individual are numerous, but in addition, the societal and global impact have been highlighted by a recent publication from China which projects that a complete cessation of tobacco and solid-fuel use would reduce the TB incidence by $14-52 \%$ by 2033 [26].

Immunological mechanisms that underpin the mechanistic link between smoking and TB are unclear, although several have been proposed $[6,27]$. A large body of scientific evidence in noncigarette-smoke-associated animal and human models suggests that macrophages, CD4+ and CD8+ T-cells [28-30], apoptosis of infected cells [31, 32], autophagy [33, 34], anti-mycobacterial peptides [35, 36], interferon (IFN)- $\gamma$, interleukin (IL)-12 and tumour necrosis factor (TNF)- $\alpha$ are important in host immunity against $M$. tuberculosis [37]. In models not using TB organisms

\begin{tabular}{|c|c|c|c|}
\hline TABLE 1 & $\begin{array}{l}\text { Associations betwee } \\
\text { risk of latent tubercl } \\
\text { progression to activ } \\
\text { active TB disease }\end{array}$ & $\begin{array}{l}\text { smoking ar } \\
\text { sis (TB) infe } \\
\text { disease and }\end{array}$ & $\begin{array}{l}\text { the relative } \\
\text { ion, } \\
\text { iortality from }\end{array}$ \\
\hline \multirow[t]{2}{*}{ Meta-analysis } & \multicolumn{3}{|c|}{ Pooled relative risk $(95 \% \mathrm{Cl})$} \\
\hline & TB infection & TB disease & TB mortality \\
\hline Studies n & $\sim 6$ & $\sim 15$ & $\sim 5$ \\
\hline SLAma [2] & $\sim 1.8(1.5-2.1)$ & $\sim 2.3(1.8-3.0)$ & $\sim 2.2(1.3-3.7)$ \\
\hline LIN [3] & $1.7-2.2(1.5-2.8)$ & $\sim 2.0(1.6-2.6)$ & $\sim 2.0(1.1-3.5)$ \\
\hline Bates [4] & $\sim 1.7(1.5-2.0)$ & $\sim 2.3(2.0-2.8)$ & $\sim 2.1(1.4-3.4)$ \\
\hline
\end{tabular}


or antigens, cigarette smoke selectively downregulates the production of IL-12 and TNF- $\alpha$ [38]. Nicotine, through an interaction with $\alpha 7$ nicotinic acetylcholine receptors, enhances the replication of intracellular organisms such as Legionella and turns off production of TNF- $\alpha$ by macrophages while leaving the secretion of IL-10 intact [39].

Cigarette smoke also prevents pathogen-specific expansion and activation of CD4+ T-cells [40] and reduces IFN- $\gamma$ producing adenoid-specific CD4+ and CD8+ T-cell numbers [41]. Other potential mechanisms whereby smoking may attenuate host defence mechanisms include oxidative stress at the site of infection and impairment or mechanical disruption of cilial function in the tracheobronchial tree [17].

\section{TB AND HIV}

The effect of the HIV epidemic on TB has been well documented, with incident rates of TB, particularly in Africa, rising rapidly as a result of HIV [21]. The risk of active TB doubles in the first year of HIV co-infection [42], and the risk of developing active disease in those who have LTBI is $\sim 10 \%$ per yr [43]. HIV-TB co-infected individuals have reduced survival [44] and are at higher risk for subsequent opportunistic infections $[45,46]$. In overcrowded and poor living conditions, the combined effect of the two epidemics is magnified as evidenced by $>2,000$ per 100,000 population prevalence rates in certain South African communities [47]. Added complications in co-infected individuals include drug-resistant TB and immune reconstitution inflammatory syndrome [48].

Strategies to combat the epidemics include: improvement of socioeconomic conditions and political stability; development and access to improved drugs, diagnostic tools and vaccines; improved access to treatment, addressing gender and operational research questions; and combining the efforts of TB control and HIV treatment programmes. Broad access to antiretroviral therapy and TB control measures will help to control the epidemic $[5,47,49,50]$. It is noteworthy that in many parts of Africa poverty has worsened in the last decade, and the global economic downturn is likely to make the millennium development goals more difficult to attain.

\section{ASSOCIATIONS BETWEEN TOBACCO SMOKE AND HIV}

$\mathrm{HIV}$ is driving the TB epidemic as previously mentioned. If tobacco smoking increases the impact of TB in HIV-negative individuals, its effect in HIV-positive individuals may be significantly greater. Preliminary data from a small study in sub-Saharan Africa supports the association of tobacco smoke and TB in HIV-infected individuals [51]. Larger studies will be required to compare the magnitude of the effect between HIVinfected and uninfected populations.

Although both tobacco smoking and HIV infection may be associated through their common links with poverty and highrisk behaviour, tobacco smoking appears to be an independent and important risk factor for contracting HIV [52-55]. Other studies have demonstrated higher viral loads [56] and rate of progression of HIV infection to AIDS in smokers [57, 58], but this association has not been observed in all studies [59-62]. A possible reason for the conflicting results might be the many confounding factors, such as nutritional status, alcohol and poverty, which may have masked the association.
Other health consequences of tobacco smoking in HIV-infected individuals include the risk of TB, pneumonia and malignancy. Miguez-Burbano et al. [63] showed a doubling of the risk of developing TB in HIV-positive people who smoke. Several studies have demonstrated an increased risk (1.5-2.6 times higher) of community-acquired bacterial pneumonia in those who smoke [64-68]. It is not clear whether this applies to Pneumocystis jiroveci pneumonia (PCP): some studies showed a two- to three-fold increased risk of developing PCP in smokers [67], but others did not [60, 65, 66]. HIV-infected people are at increased risk of Kaposi's sarcoma and lymphoma, as well as primary lung cancer. With increased life expectancy achieved with antiretroviral therapy, the risk of lung cancer from smoking is likely to increase further [69].

The use of combination antiretroviral therapy has dramatically reduced the incidence of opportunistic infections in HIVinfected subjects [70-72]. However, LE MoING et al. [70] found that, although the risk for bacterial pneumonia is reduced by antiretroviral therapy, the magnitude of this reduction was significantly less in smokers. Evidence from the communitybased studies in high-burden countries suggests that merely raising a single individual's CD4 count may not be sufficient to reduce the burden of disease if overcrowding, alcohol and tobacco smoking are not adequately addressed.

In smokers, HIV infection appears to cause a form of accelerated emphysema in young HIV-positive individuals. This is discussed below.

\section{TB, HIV, SMOKING AND BIOMASS FUELS AS RISK FACTORS FOR COPD}

Causality between tobacco smoke and COPD is well established and it remains the primary risk factor for COPD [73]. As well as the documented dose-dependent risk of COPD from tobacco smoke [74], the importance of the "total burden of inhaled particles", including occupational, household and environmental exposures, is increasingly being recognised [75-78]. An estimated $50 \%$ of all households worldwide ( $\sim 3$ billion people) use solid fuels for cooking and heating [79]. Indoor biomass fuel burning, in addition to air pollution, has been well documented in case-control studies to be a significant risk factor for COPD (odds ratios (ORs) ranging from 1.35 to $6.61[8,9,13,80]$ ). Moreover, projections from these studies highlight the global risk, in particular to females in developing countries, of obstructive airway disease from biomass fuel exposure.

Infections, particularly in childhood, have been regarded as risk factors for COPD [81]. Post-tuberculous "obstructive airways disease" was described in the medical literature in the 1950s and 1960s by several authors [82-85]. MARTIN and HALLET [84] reported that "It is increasingly evident that a diffuse obstructive pulmonary syndrome is often associated with tuberculosis". They further make reference to the documentation of emphysema and TB by Laennec in the 1800s [83]. Although this association continues to be widely recognised by clinicians in developing countries [86-88], it has been poorly studied [88, 89]. A nationwide survey in South Africa, a high-prevalence country for $\mathrm{TB}$, has demonstrated that a history of previous TB is a strong predictor of chronic bronchitis (OR 4.9, 95\% CI 2.6-9.2 in males; OR 6.6, 95\% CI 3.711.9 in females) [11]. In addition, several clinical studies have 
confirmed airflow limitation as a consequence of tuberculous disease $[78,86,88,90]$. International comparisons of COPD prevalence using the Burden of Obstructive Lung Disease methodology [10,75] and a similar study from Latin America [91] have identified previous TB as a risk factor for COPD. Absence of detailed clinical information in these surveys prevents conclusions about pathophysiology and whether such cases fall within the definitions of clinical COPD or represent one or several other forms of structural lung disease.

In addition to the burden of tobacco smoking, air pollution (indoor and environmental) and poverty, HIV is prevalent in many developing countries, particularly in sub-Saharan Africa. HIV infection alone is increasingly being recognised as a cause of premature emphysema [92-96]. Two recent reviews by CROTHERs [12] and PETRACHe et al. [96] have highlighted current knowledge on this association. It would appear that emphysema occurs earlier, with fewer pack-yrs of smoking, and may be associated with colonisation by $P$. jiroveci. In addition to the complex pathological pathways identified in HIV-negative smokers, excess cytotoxic T-lymphocyte activity, endothelial dysfunction and increased apoptosis have been suggested as possible pathological mechanisms. The natural history of COPD in HIV is unclear. It is also not known if the use of anti-inflammatory or bronchodilator therapy is of any value or if antiretroviral therapy will halt the development, or progression, of the disease. Long-term follow-up and therapeutic intervention trials are needed.

\section{PUBLIC HEALTH AND PULMONARY IMPLICATIONS}

Patients in developing countries, especially those with a high prevalence of infectious disease, frequently present with complex lung disease resulting from the varying insults of tobacco smoke and other harmful environmental exposures, TB, HIV and COPD. The impact of current and projected exposures to these conditions will result in a heavy burden of lung diseases in resource-poor countries in coming decades. There is little prospect for improvement unless there is a concerted and coordinated effort by all involved parties, such as health authorities, practitioners, researchers and society in general. Public health measures are required to improve air quality and reduce passive exposure to tobacco smoke, reduce overcrowding, improve housing and reduce reliance on biomass fuels in homes.

Also required are access to antiretroviral therapy, measures to reduce transmission of $\mathrm{HIV}$, and the development of effective vaccines for $\mathrm{TB}$ and other respiratory pathogens, hopefully also for HIV infection. New effective drugs and diagnostic tools are urgently required. There should in addition be greater integration of $\mathrm{TB}, \mathrm{HIV}$ and respiratory services and the provision of smoking cessation programmes.

Knowledge of causal links and interactions between HIV, TB and COPD would assist with identification of novel targets for intervention and add significant scientific weight to the messages of health advocates and lobby groups campaigning for the welfare of patients.

Although the combined effects of all the epidemics may only be recognised in developing countries, the developed world is not immune to the risk. Eastern Europe has a high incidence of MDR-TB and smoking. In North America, although TB may be infrequently seen, HIV and tobacco smoking frequently coexist. The emergence of multi- and extensively drug-resistant TB pose a global threat, since spillover through migration and travel is inevitable.

\section{CONCLUSION}

Historically, TB and HIV have been the focus of infectious disease specialists, smoking and COPD the focus of pulmonologists, and biomass fuel exposure the interest of public health researchers. It is now clear that in day-to-day clinical practice a more complex picture is emerging as the epidemics of HIV, tobacco smoking and biomass fuel exposure, TB and COPD interact on a global scale. These interactions deserve urgent attention and have major implications for co-ordinated public health planning and policy recommendations in the developing world.

\section{SUPPORT STATEMENT}

R.N. van Zyl Smit is supported by a Discovery Foundation Fellowship and by the Fogarty International Clinical Research Scholars/Fellows Support Centre National Institutes of Health grant R24TW007988. M. Pai is supported by grants from the Canadian Institutes of Health Research and European Commission (TBSusgent; EU FP-7). K. Dheda is supported by the South African National Research Foundation, the South African Medical Research Council, the EC Framework 7 programme and the European and Developing Countries Clinical Trials Partnership (EDCTP), and by the University College LondonUniversity of Cape Town Collaboration Initiative. A. Zumla is in receipt of funding from the EC Framework 7 programme and EDCTP, and from EuropeAID, Brussels, Belgium. E.D. Bateman is supported by the International Development Research Centre of Canada.

\section{STATEMENT OF INTEREST}

None declared.

\section{REFERENCES}

1 Webb GB. The effect of the inhalation of cigarette smoke on the lungs. A clinical study. Am Rev Tuberc 1918; March, 25-27.

2 Slama K, Chiang CY, Enarson DA, et al. Tobacco and tuberculosis: a qualitative systematic review and meta-analysis. Int $J$ Tuberc Lung Dis 2007; 11: 1049-1061.

3 Lin HH, Ezzati M, Murray M. Tobacco smoke, indoor air pollution and tuberculosis: a systematic review and meta-analysis. PLoS Med 2007; 4: e20.

4 Bates MN, Khalakdina A, Pai M, et al. Risk of tuberculosis from exposure to tobacco smoke: a systematic review and metaanalysis. Arch Intern Med 2007; 167: 335-342.

5 Lawn SD, Bekker LG, Middelkoop K, et al. Impact of HIV infection on the epidemiology of tuberculosis in a peri-urban community in South Africa: the need for age-specific interventions. Clin Infect Dis 2006; 42: 1040-1047.

6 Dheda K, Johnson MA, Zumla A, et al. Smoking is not beneficial for tuberculosis. Am J Respir Crit Care Med 2004; 170: 821.

7 World Health OrganizationThe global burden of disease: 2004 update. Geneva, World Health Organization, 2004.

8 Orozco-Levi M, Garcia-Aymerich J, Villar J, et al. Wood smoke exposure and risk of chronic obstructive pulmonary disease. Eur Respir J 2006; 27: 542-546.

9 Sezer H, Akkurt I, Guler N, et al. A case-control study on the effect of exposure to different substances on the development of COPD. Ann Epidemiol 2006; 16: 59-62.

10 Buist AS, McBurnie MA, Vollmer WM, et al. International variation in the prevalence of COPD (the BOLD Study): a population-based prevalence study. Lancet 2007; 370: 741-750. 
11 Ehrlich RI, White N, Norman R, et al. Predictors of chronic bronchitis in South African adults. Int J Tuberc Lung Dis 2004; 8: 369-376.

12 Crothers K. Chronic obstructive pulmonary disease in patients who have HIV infection. Clin Chest Med 2007; 28: 575-587.

13 Liu S, Zhou Y, Wang X, et al. Biomass fuels are the probable risk factor for chronic obstructive pulmonary disease in rural South China. Thorax 2007; 62: 889-897.

14 Furber AS, Maheswaran R, Newell JN, et al. Is smoking tobacco an independent risk factor for HIV infection and progression to AIDS? A systemic review. Sex Transm Infect 2007; 83: 41-46.

15 Baris E, Ezzati M. Should interventions to reduce respirable pollutants be linked to tuberculosis control programmes? BMJ 2004; 329: 1090-1093.

16 Chiang CY, Slama K, Enarson DA. Associations between tobacco and tuberculosis. Int J Tuberc Lung Dis 2007; 11: 258-262.

17 Davies PD, Yew WW, Ganguly D, et al. Smoking and tuberculosis: the epidemiological association and immunopathogenesis. Trans $R$ Soc Trop Med Hyg 2006; 100: 291-298.

18 Maurya V, Vijayan VK, Shah A. Smoking and tuberculosis: an association overlooked. Int J Tuberc Lung Dis 2002; 6: 942-951.

19 Pai M, Mohan A, Dheda K, et al. Lethal interaction: the colliding epidemics of tobacco and tuberculosis. Expert Rev Anti Infect Ther 2007; 5: 385-391.

20 World Health Organization, International Union Against Tuberculosis and Lung DiseaseA WHO/The Union monograph on TB and tobacco control: joining efforts to control two related global epidemics. WHO/HTM/TB/2007.390. Geneva, World Health Organization, 2007.

21 World Health OrganizationGlobal tuberculosis control: epidemiology, strategy, financing. WHO report 2009. WHO/HTM/TB/ 2009.411. Geneva, World Health Organization, 2009.

22 UNAIDS, World Health Organization2007 AIDS epidemics update. Available from www.unaids.org/en/KnowledgeCentre/ HIVData/EpiUpdate/EpiUpdArchive/2007

23 De Cock KM, De Lay P. HIV/AIDS estimates and the quest for universal access. Lancet 2008; 371: 2068-2070.

24 World Health OrganizationWHO Report on the Global Tobacco Epidemic, 2008. The MPOWER package. Geneva, World Health Organization, 2008.

25 Mannino DM, Buist AS. Global burden of COPD: risk factors, prevalence, and future trends. Lancet 2007; 370: 765-773.

26 Lin HH, Murray M, Cohen T, et al. Effects of smoking and solidfuel use on COPD, lung cancer, and tuberculosis in China: a timebased, multiple risk factor, modelling study. Lancet 2008; 372: 1473-1483.

27 Rook GA, Dheda K, Zumla A. Immune responses to tuberculosis in developing countries: implications for new vaccines. Nat Rev Immunol 2005; 5: 661-667.

28 Grotzke JE, Lewinsohn DM. Role of CD8+ T lymphocytes in control of Mycobacterium tuberculosis infection. Microbes Infect 2005; 7: 776-788.

29 Caruso AM, Serbina N, Klein E, et al. Mice deficient in CD4 T cells have only transiently diminished levels of IFN- $\gamma$, yet succumb to tuberculosis. J Immunol 1999; 162: 5407-5416.

30 Serbina NV, Flynn JL. Early emergence of CD8(+) T cells primed for production of type 1 cytokines in the lungs of Mycobacterium tuberculosis-infected mice. Infect Immun 1999; 67: 3980-3988.

31 Molloy A, Laochumroonvorapong P, Kaplan G. Apoptosis, but not necrosis, of infected monocytes is coupled with killing of intracellular bacillus Calmette-Guerin. J Exp Med 1994; 180: 1499-1509.

32 Keane J, Remold HG, Kornfeld H. Virulent Mycobacterium tuberculosis strains evade apoptosis of infected alveolar macrophages. J Immunol 2000; 164: 2016-2020.

33 Harris J, De Haro SA, Master SS, et al. T helper 2 cytokines inhibit autophagic control of intracellular Mycobacterium tuberculosis. Immunity 2007; 27: 505-517.
34 Levine B, Deretic V. Unveiling the roles of autophagy in innate and adaptive immunity. Nat Rev Immunol 2007; 7: 767-777.

35 Ernst WA, Thoma-Uszynski S, Teitelbaum R, et al. Granulysin, a T cell product, kills bacteria by altering membrane permeability. $J$ Immunol 2000; 165: 7102-7108.

36 Stenger S, Hanson DA, Teitelbaum R, et al. An antimicrobial activity of cytolytic T cells mediated by granulysin. Science 1998; 282: 121-125.

37 Borovikova LV, Ivanova S, Zhang $\mathrm{M}$, et al. Vagus nerve stimulation attenuates the systemic inflammatory response to endotoxin. Nature 2000; 405: 458-462.

38 Robbins CS, Dawe DE, Goncharova SI, et al. Cigarette smoke decreases pulmonary dendritic cells and impacts antiviral immune responsiveness. Am J Respir Cell Mol Biol 2004; 30: 202-211.

39 Matsunaga K, Klein TW, Friedman $\mathrm{H}$, et al. In vitro therapeutic effect of epigallocatechin gallate on nicotine-induced impairment of resistance to Legionella pneumophila infection of established MH-S alveolar macrophages. J Infect Dis 2002; 185: 229-236.

40 Avanzini MA, Ricci A, Scaramuzza C, et al. Deficiency of INF $\gamma$ producing cells in adenoids of children exposed to passive smoke. Int J Immunopathol Pharmacol 2006; 19: 609-616.

41 Tomita K, Caramori G, Lim S, et al. Increased p21(CIP1/WAF1) and $\mathrm{B}$ cell lymphoma leukemia-x(L) expression and reduced apoptosis in alveolar macrophages from smokers. Am J Respir Crit Care Med 2002; 166: 724-731.

42 Sonnenberg P, Glynn JR, Fielding K, et al. How soon after infection with HIV does the risk of tuberculosis start to increase? A retrospective cohort study in South African gold miners. J Infect Dis 2005; 191: 150-158.

43 Selwyn PA, Hartel D, Lewis VA, et al. A prospective study of the risk of tuberculosis among intravenous drug users with human immunodeficiency virus infection. N Engl J Med 1989; 320: 545-550.

44 Whalen C, Horsburgh CR, Hom D, et al. Accelerated course of human immunodeficiency virus infection after tuberculosis. Am J Respir Crit Care Med 1995; 151: 129-135.

45 Dheda K, Lampe FC, Johnson MA, et al. Outcome of HIVassociated tuberculosis in the era of highly active antiretroviral therapy. J Infect Dis 2004; 190: 1670-1676.

46 Munsiff SS, Alpert PL, Gourevitch MN, et al. A prospective study of tuberculosis and HIV disease progression. J Acquir Immune Defic Syndr Hum Retrovirol 1998; 19: 361-366.

47 Wood R, Middelkoop K, Myer L, et al. Undiagnosed tuberculosis in a community with high HIV prevalence: implications for tuberculosis control. Am J Respir Crit Care Med 2007; 175: 87-93.

48 Dhasmana DJ, Dheda K, Ravn P, et al. Immune reconstitution inflammatory syndrome in HIV-infected patients receiving antiretroviral therapy: pathogenesis, clinical manifestations and management. Drugs 2008; 68: 191-208.

49 Wood R. The case for integrating tuberculosis and HIV treatment services in South Africa. J Infect Dis 2007; 196: S497-S499.

50 Williams BG, Dye C. Antiretroviral drugs for tuberculosis control in the era of HIV/AIDS. Science 2003; 301: 1535-1537.

51 Ramin B, Kam D, Feleke B, et al. Smoking, HIV and non-fatal tuberculosis in an urban African population. Int J Tuberc Lung Dis 2008; 12: 695-697.

52 Boulos R, Halsey NA, Holt E, et al. HIV-1 in Haitian women 1982 1988. The Cite Soleil/JHU AIDS Project Team. J Acquir Immune Defic Syndr 1990; 3: 721-728.

53 Halsey NA, Coberly JS, Holt E, et al. Sexual behavior, smoking, and HIV-1 infection in Haitian women. JAMA 1992; 267: 2062-2066.

54 Chao A, Bulterys M, Musanganire F, et al. Risk factors associated with prevalent HIV-1 infection among pregnant women in Rwanda. National University of Rwanda-Johns Hopkins University AIDS Research Team. Int J Epidemiol 1994; 23: 371-380.

55 Penkower L, Dew MA, Kingsley L, et al. Behavioral, health and psychosocial factors and risk for HIV infection among sexually 
active homosexual men: the Multicenter AIDS Cohort Study. Am J Public Health 1991; 81: 194-196.

56 Wojna V, Robles L, Skolasky RL, et al. Associations of cigarette smoking with viral immune and cognitive function in human immunodeficiency virus-seropositive women. J Neurovirol 2007; 13: $561-568$.

57 Nieman RB, Fleming J, Coker RJ, et al. The effect of cigarette smoking on the development of AIDS in HIV-1-seropositive individuals. AIDS 1993; 7: 705-710.

58 Feldman JG, Minkoff H, Schneider MF, et al. Association of cigarette smoking with HIV prognosis among women in the HAART era: a report from the women's interagency HIV study. Am J Public Health 2006; 96: 1060-1065.

59 Eskild A, Petersen G. Cigarette smoking and drinking of alcohol are not associated with rapid progression to acquired immunodeficiency syndrome among homosexual men in Norway. Scand J Soc Med 1994; 22: 209-212.

60 Galai N, Park LP, Wesch J, et al. Effect of smoking on the clinical progression of HIV-1 infection. J Acquir Immune Defic Syndr Hum Retrovirol 1997; 14: 451-458.

61 Craib KJ, Schechter MT, Montaner JS, et al. The effect of cigarette smoking on lymphocyte subsets and progression to AIDS in a cohort of homosexual men. Clin Invest Med 1992; 15: 301-308.

62 Webber MP, Schoenbaum EE, Gourevitch MN, et al. A prospective study of HIV disease progression in female and male drug users. AIDS 1999; 13: 257-262.

63 Miguez-Burbano MJ, Burbano X, Ashkin D, et al. Impact of tobacco use on the development of opportunistic respiratory infections in HIV seropositive patients on antiretroviral therapy. Addict Biol 2003; 8: 39-43.

64 Kohli R, Lo Y, Homel P, et al. Bacterial pneumonia, HIV therapy, and disease progression among HIV-infected women in the HIV epidemiologic research (HER) study. Clin Infect Dis 2006; 43: 90-98.

65 Burns DN, Hillman D, Neaton JD, et al. Cigarette smoking, bacterial pneumonia, and other clinical outcomes in HIV-1 infection. Terry Beirn Community Programs for Clinical Research on AIDS. J Acquir Immune Defic Syndr Hum Retrovirol 1996; 13: 374-383.

66 Conley LJ, Bush TJ, Buchbinder SP, et al. The association between cigarette smoking and selected HIV-related medical conditions. AIDS 1996; 10: 1121-1126.

67 Miguez-Burbano MJ, Ashkin D, Rodriguez A, et al. Increased risk of Pneumocystis carinii and community-acquired pneumonia with tobacco use in HIV disease. Int I Infect Dis 2005; 9: 208-217.

68 Crothers K, Griffith TA, McGinnis KA, et al. The impact of cigarette smoking on mortality, quality of life, and comorbid illness among HIV-positive veterans. J Gen Intern Med 2005; 20: 1142-1145.

69 Kirk GD, Merlo C, O'Driscoll P, et al. HIV infection is associated with an increased risk for lung cancer, independent of smoking. Clin Infect Dis 2007; 45: 103-110.

70 Le Moing V, Rabaud C, Journot V, et al. Incidence and risk factors of bacterial pneumonia requiring hospitalization in HIV-infected patients started on a protease inhibitor-containing regimen. HIV Med 2006; 7: 261-267.

71 Madeddu G, Porqueddu E, Cambosu F, et al. Bacterial community acquired pneumonia in HIV-infected inpatients in the highly active antiretroviral therapy era. Infection 2008; 36: 231-236.

72 Curran A, Falco V, Crespo M, et al. Bacterial pneumonia in HIVinfected patients: use of the pneumonia severity index and impact of current management on incidence, aetiology and outcome. HIV Med 2008; 9: 609-615.

73 Rabe KF, Hurd S, Anzueto A, et al. Global strategy for the diagnosis, management, and prevention of chronic obstructive pulmonary disease: GOLD executive summary. Am J Respir Crit Care Med 2007; 176: 532-555.
74 Burrows B, Knudson RJ, Cline MG, et al. Quantitative relationships between cigarette smoking and ventilatory function. Am Rev Respir Dis 1977; 115: 195-205.

75 Buist AS, Vollmer WM, Sullivan SD, et al. The Burden of Obstructive Lung Disease Initiative (BOLD): rationale and design. COPD 2005; 2: 277-283.

76 Grobbelaar JP, Bateman ED. Hut lung: a domestically acquired pneumoconiosis of mixed aetiology in rural women. Thorax 1991; 46: 334-340.

77 Weinmann S, Vollmer WM, Breen V, et al. COPD and occupational exposures: a case-control study. J Occup Environ Med 2008; 50 561-569.

78 Gothi D, Shah DV, Joshi JM. Clinical profile of diseases causing chronic airflow limitation in a tertiary care centre in India. $J$ Assoc Physicians India 2007; 55: 551-555.

79 Torres-Duque C, Maldonado D, Perez-Padilla R, et al. Biomass fuels and respiratory diseases: a review of the evidence. Proc Am Thorac Soc 2008; 5: 577-590.

80 Zhong N, Wang C, Yao W, et al. Prevalence of chronic obstructive pulmonary disease in China: a large, population-based survey. Am I Respir Crit Care Med 2007; 176: 753-760.

81 Shaheen SO, Barker DJ, Shiell AW, et al. The relationship between pneumonia in early childhood and impaired lung function in late adult life. Am J Respir Crit Care Med 1994; 149: 616-619.

82 Anno H, Tomashefski JF. Studies on the impairment of respiratory function in pulmonary tuberculosis. Am Rev Tuberc 1955; 71: 333-348,

83 Hallett WY, Martin CJ. The diffuse obstructive pulmonary syndrome in a tuberculosis sanatorium. I. Etiologic factors. Ann Intern Med 1961; 54: 1146-1155.

84 Martin CJ, Hallett WY. The diffuse obstructive pulmonary syndrome in a tuberculosis sanatorium. II. Incidence and symptoms. Ann Intern Med 1961; 54: 1156-1164.

85 Birath G, Caro J, Malmberg R, et al. Airways obstruction in pulmonary tuberculosis. Scand J Respir Dis 1966; 47: 27-36.

86 Willcox PA, Ferguson AD. Chronic obstructive airways disease following treated pulmonary tuberculosis. Respir Med 1989; 83: 195-198.

87 Dheda K, Booth $\mathrm{H}$, Huggett JF, et al. Lung remodeling in pulmonary tuberculosis. J Infect Dis 2005; 192: 1201-1209.

88 Plit ML, Anderson R, Van Rensburg CE, et al. Influence of antimicrobial chemotherapy on spirometric parameters and proinflammatory indices in severe pulmonary tuberculosis. Eur Respir J 1998; 12: 351-356.

89 Jung KH, Kim SJ, Shin C, et al. The considerable, often neglected, impact of pulmonary tuberculosis on the prevalence of COPD. Am J Respir Crit Care Med 2008; 178: 431.

90 Hnizdo E, Singh T, Churchyard G. Chronic pulmonary function impairment caused by initial and recurrent pulmonary tuberculosis following treatment. Thorax 2000; 55: 32-38.

91 Menezes AM, Hallal PC, Perez-Padilla R, et al. Tuberculosis and airflow obstruction: evidence from the PLATINO study in Latin America. Eur Respir J 2007; 30: 1180-1185.

92 Kuhlman JE, Knowles MC, Fishman EK, et al. Premature bullous pulmonary damage in AIDS: CT diagnosis. Radiology 1989; 173: 23-26.

93 Diaz PT, King MA, Pacht ER, et al. Increased susceptibility to pulmonary emphysema among HIV-seropositive smokers. Ann Intern Med 2000; 132: 369-372.

94 Diaz PT, King ER, Wewers MD, et al. HIV infection increases susceptibility to smoking-induced emphysema. Chest 2000; 117: 285 S.

95 Crothers K, Butt AA, Gibert CL, et al. Increased COPD among HIV-positive compared to HIV-negative veterans. Chest 2006; 130: 1326-1333.

96 Petrache I, Diab K, Knox KS, et al. HIV associated pulmonary emphysema: a review of the literature and inquiry into its mechanism. Thorax 2008; 63: 463-469. 